\title{
Identification of carriers of Duchenne/Becker muscular dystrophy by a novel method based on detection of junction fragments in the dystrophin gene
}

Department of University School of Medicine, Tokyo, Japan

H Yamagishi

N Matsuo

\section{Department of}

Microbiology, Keio

University School of

Medicine, 35

Shinanomachi,

Shinjuku-ku,

Tokyo 160, Japan

S Kato

Y Hiraishi

$\mathrm{T}$ Takano

Department of Pathology, Keio

University School of Medicine, Tokyo,

Japan

J Hata

National HigashiSaitama Hospital, Hasuda, Saitama, Japan

T Ishihara

Correspondence to: Dr Kato.

Received 5 March 1996 Revised version accepted for publication

3 September 1996
H Yamagishi, S Kato, Y Hiraishi, T Ishihara, J Hata, N Matsuo, T Takano out using quantitative Southern blot hybridisation.

( $f$ Med Genet 1996;33:1027-1031)

Key words: Duchenne/Becker muscular dystrophy; junction fragment; carrier diagnosis; Southern blotting

Duchenne muscular dystrophy (DMD), a lethal muscle wasting disease, is allelic with Becker muscular dystrophy (BMD), a clinically similar but milder form of myopathy. ${ }^{1}$ Both $\mathrm{DMD}$ and $\mathrm{BMD}$ are $\mathrm{X}$ linked recessive disorders characterised by frequent de novo mutations of the dystrophin gene. Studies using Southern blot hybridisation have shown that deletions or duplications of DNA containing one or more dystrophin exons are responsible for approximately $70 \%$ of $\mathrm{DMD} / \mathrm{BMD}$ cases. ${ }^{2-10}$ Female carriers of rearranged dystrophin genes can be identified by quantitative Southern blot analysis. However, because signal intensities of the hybridised bands must be measured accurately, results are occasionally ambiguous. ${ }^{11-13}$

Junction fragments produced by gross alterations of the dystrophin gene are observed in some cases. Such fragments are disease specific markers of carriers of rearranged dystrophin genes and the detection of them is less ambiguous than the analysis of gene dosage. ${ }^{4613}$ However, because junction fragments are detected by conventional Southern blot hybridisation in only a small percentage of patients with $\mathrm{DMD} / \mathrm{BMD},{ }^{4610}$ they have not proven useful. We developed a novel Southern blotting based method to detect junction fragments. To determine whether this method can be used to identify carriers of abnormal dystrophin genes, we compared the ability of this technique and conventional Southern blotting to detect junction fragments in patients with $\mathrm{DMD}$ or $\mathrm{BMD}$ and their families.

\section{Materials and methods}

SUBJECTS

We studied 27 unrelated Japanese male patients in 27 families and six female members of two of the families. Of the 27 patients, 19 with DMD and one with BMD carried partial deletions and the remaining seven DMD patients carried partial duplications in the dystrophin gene. No junction fragments were detected in any of the patients by Southern blot hybridisation using HindIII digestion. ${ }^{10}$ Thirteen normal Japanese men were used as controls. 
A

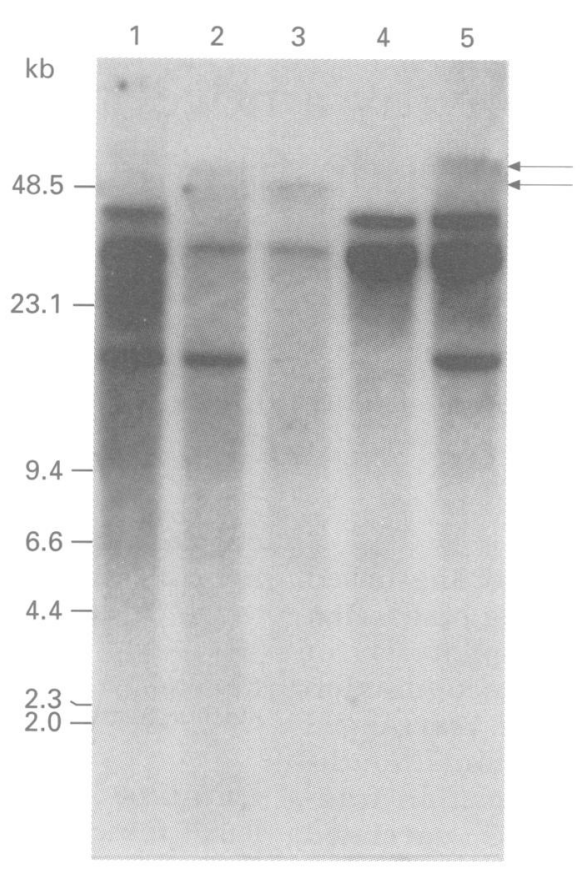

C



B

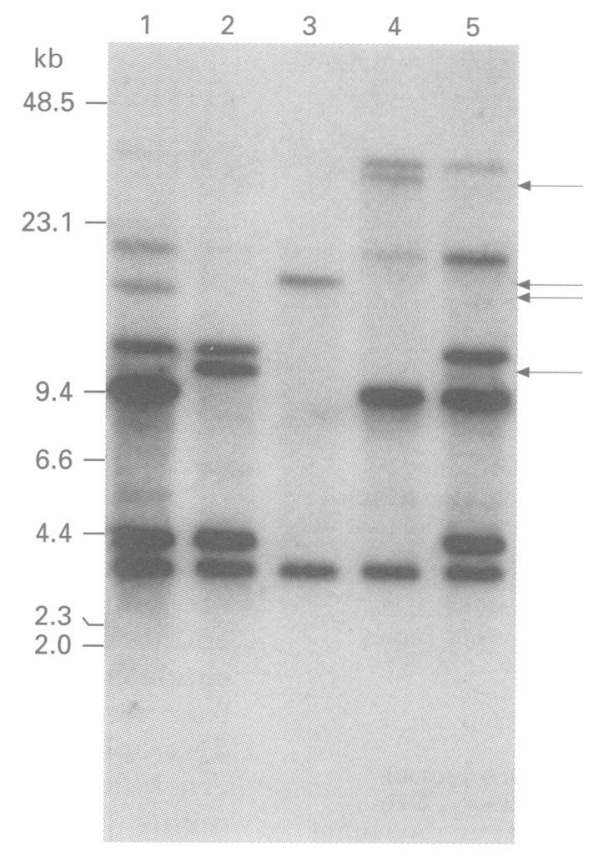

D



Figure 2 The detection of junction fragments in the dystrophin gene. The DNA of patients 21 (lane 1), 7 (lane 2), 10 (lane 3), and 9 (lane 4), and a normal male was digested with ApaI (A), BstPI (B), EcoRV (C), and KpnI (D), and hybridised with the probe of $c D N A 8$. Patient 21 had a duplication and patients 7,10 , and 9 had deletions in the region of $c D N A 8$. The locations of molecular weight markers are indicated on the left, and junction fragments are indicated by arrows on the right.

PROBES AND RESTRICTION ENDONUCLEASES

Probes of dystrophin cDNA ${ }^{2}$ 1-2a, 2b-3, 4-5a, 5b-7, 8, and 9-14 were obtained from the American Type Culture Collection. Restriction endonucleases $A p a \mathrm{I}, B s t \mathrm{PI}, E c o \mathrm{RV}$, and $K p n \mathrm{I}$ were used, as they are rare cutters and their recognition sites carry no $C G$ sequences that are susceptible to methylation.

\section{DNA PREPARATION}

Genomic DNA was prepared from peripheral blood by a conventional lysis method. ${ }^{14}$ Briefly, anticoagulated blood was treated with a hypotonic solution $\left(155 \mathrm{mmol} / 1 \quad \mathrm{NH}_{4} \mathrm{Cl}\right.$, $10 \mathrm{mmol} / 1 \mathrm{NH}_{4} \mathrm{HCO}_{3}, 1 \mathrm{mmol} / 1$ EDTA, $\mathrm{pH}$ 7.4). From the remaining cells, DNA was liberated with sodium dodecyl sulphate and proteinase $\mathrm{K}$ and then extracted with phenol and chloroform.

ELECTROPHORESIS OF SINGLE STRANDED DNA DNA was digested to completion with one of the restriction enzymes and precipitated with ethanol. The DNA was then incubated at $50^{\circ} \mathrm{C}$ for one hour in a solution of $1.0 \mathrm{~mol} / 1$ glyoxal and $50 \%(\mathrm{v} / \mathrm{v})$ dimethyl sulphoxide to denature 
Restriction endonucleases

Patients that detected junction

fragments

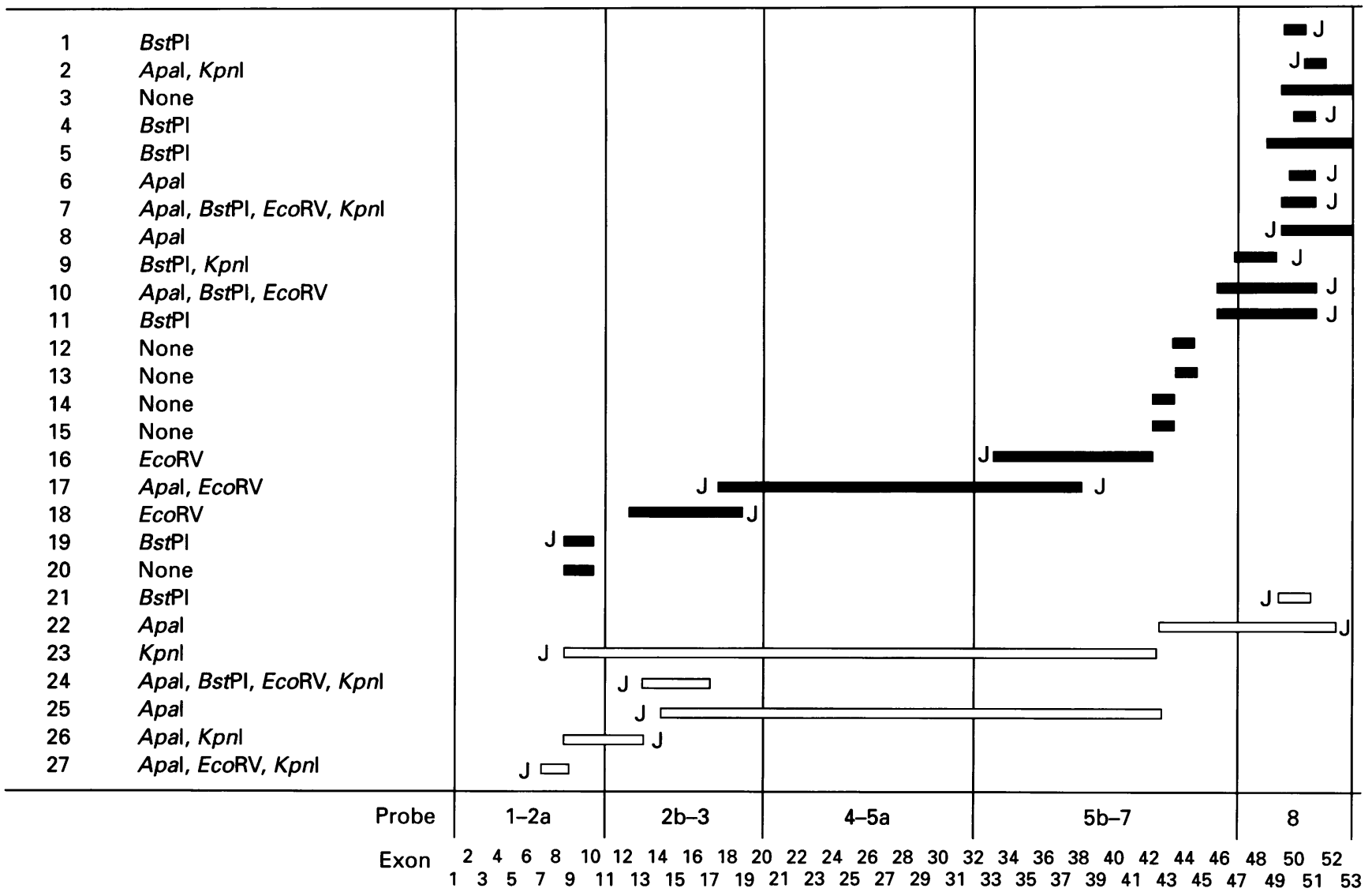

Figure 3 function fragments of the dystrophin gene observed in the present study. The extents of deletions and duplications which had been determined in our previous study ${ }^{10}$ are shown on a map of the dystrophin cDNA. Closed bars, deletions; open bars, duplications; $\mathcal{F}$, the end point of the rearranged region responsible for generating the junction fragment.

the double stranded conformation and to disrupt the secondary structure. ${ }^{15}$ Five micrograms of the single stranded DNA were electrophoresed in $0.4 \%$ agarose (FastLane or SeaKem Gold Agarose, FMC) gel in $0.01 \mathrm{~mol} / 1$ sodium phosphate buffer, $\mathrm{pH}$ 7.0.

SOUTHERN BLOT HYBRIDISATION

The electrophoresed single stranded DNA in gel was transferred to Hybond-N + membrane (Amersham) and hybridised with ${ }^{32} \mathrm{P}$ labelled probes of dystrophin cDNA, as described previously. ${ }^{1016}$

\section{Results}

COMPARISON OF ELECTROPHORESIS OF SINGLE AND DOUBLE STRANDED DNA

Electrophoresis of single stranded DNA had a higher ability to separate large DNA fragments, particularly those larger than $20 \mathrm{~kb}$, than conventional electrophoresis (fig 1). After digestion with $A p a \mathrm{I}$ or KpnI, some bands that appeared to be single bands on conventional electrophoresis were separated into double or triple bands by electrophoresis of single stranded DNA.
DETECTION OF JUNCTION FRAGMENTS IN PATIENTS WITH DMD/BMD

After digestion with $A p a \mathrm{I}, B s t \mathrm{PI}, E c o \mathrm{RV}$, or $K p n I, 22$ DNA fragments of unusual length were detected by Southern blotting of single stranded DNA in 14 of 20 patients with deletions in the dystrophin gene, six by $A p a \mathrm{I}$ digestion, eight by $B s t \mathrm{PI}$, five by $E c o \mathrm{RV}$, and three by $K p n I$ (fig 2). Because such fragments were not observed in the DNA of control subjects, they were considered to be junction fragments. By similar analysis, 12 junction fragments were detected in the seven patients with duplications, five by $A p a \mathrm{I}$, two by $B s t \mathrm{PI}$, one by $E c o \mathrm{RV}$, and four by $K p n \mathrm{I}$. The locations of these junction fragments were mapped on the dystrophin cDNA (fig 3).

IDENTIFICATION OF CARRIERS WITH FAMILY SPECIFIC JUNCTION FRAGMENTS

We tried to identify carriers in two families by the method described above. Patients 10 and 27 carried a deletion and a duplication, respectively, in the dystrophin gene. In the family of patient 10 , a $20 \mathrm{~kb}$ junction fragment was detected in the DNA of the proband, his 
A


B
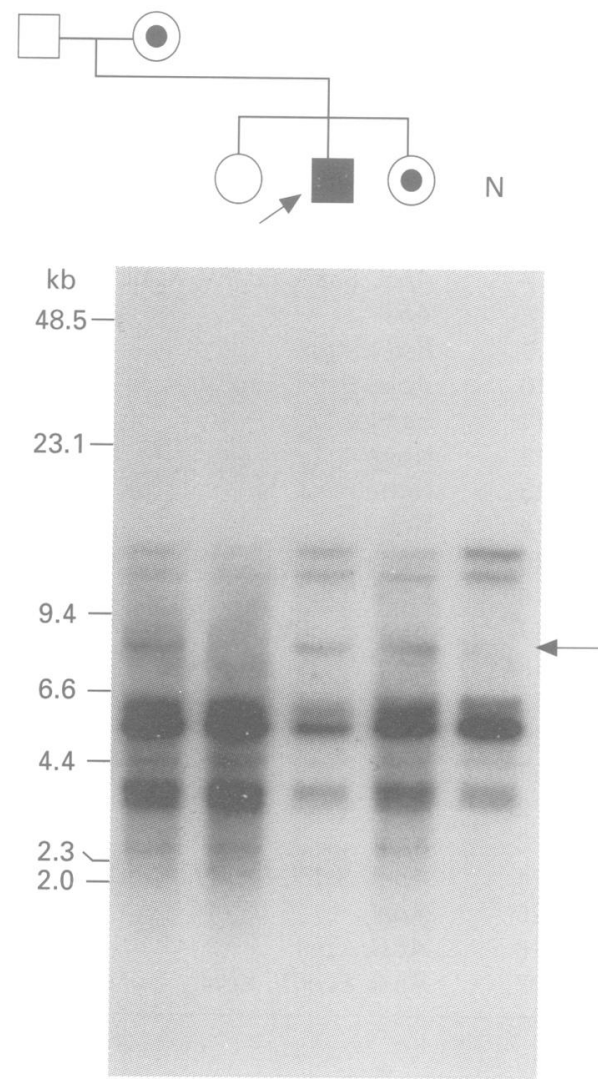

Figure 4 (A) Identification of carriers in the family of patient 10. The proband carried a deletion in the region of the $c D N A 8$ probe. The DNA from members of the family and a normal male $(N)$ was digested with BstPI and hybridised with the probe of dystrophin cDNA8. Function fragments of $20 \mathrm{~kb}$ (arrows) were detected in the DNA of all family members. (B) Identification of carriers in the family of patient 27. The proband carried a duplication in the region of the cDNA1-2a probe. The DNA from members of the family and a normal male (N) was digested with EcoRV and hybridised with the probe of dystrophin cDNA1-2a. Function fragments of 8 kb (arrows) were detected in the DNA of the patient, his mother, and younger sister.

mother, sister, and female cousin (fig 4A). Thus, all of these family members were carriers of the same deletion in the dystrophin gene. In patient 27 , an $8 \mathrm{~kb}$ junction fragment was detected in his DNA (fig 4B, lane 3). Because his mother and younger sister had similar bands in their DNA (fig 4B, lanes 1 and 4), they should have carried the same duplication in the dystrophin gene. His older sister was not a carrier, as no junction fragment was detected in her DNA (fig 4B, lane 2).

\section{Discussion}

Carriers of DMD/BMD can be unambiguously identified through detection of junction fragments in the dystrophin gene. We developed a Southern blotting based method that uses rare cutting restriction endonucleases and electrophoresis of single stranded DNA to detect junction fragments efficiently. Using this method, we detected junction fragments in 21 of 27 (78\%) randomly selected patients with DMD/ BMD who carried deletions or duplications in the dystrophin gene. In our previous study, ${ }^{10}$ junction fragments were detected by conventional Southern blot hybridisation in 10 of $59(17 \%)$ patients. It is difficult to identify carriers by quantitative Southern blot analysis. ${ }^{4}$ In particular, for identification of carriers with partial duplications in the dystrophin gene, the intensity of hybridisation signals must be accurately determined to distinguish the band corresponding to three copies per cell from that corresponding to two copies per cell. On the other hand, junction fragments are easily identified as DNA fragments of unusual size which are generated by genetic disorders. Analysis using restriction fragment length polymorphisms is also used for carrier detection but is limited owing to genetic recombination, ${ }^{11}$ which is not a problem in the analysis using junction fragments.

The efficiency of detection of junction fragments can be maximised by the use of rare cutting restriction endonucleases and pulsed field gel electrophoresis (PFGE). Den Dunnen et $a l^{6}$ reported PFGE analysis of DMD and found junction fragments in 23 out of 128 cases. PFGE is a useful technique to separate extremely large DNA fragments. However, it has disadvantages including the need for expensive specialised equipment, and more importantly the need for specially prepared high molecular weight genomic DNA samples, which usually depend on the acquisition of 
fresh blood samples. Our method is simpler than PFGE in separation of DNA fragments of up to $50 \mathrm{~kb}$, because it has no need for specialised equipment. Moreover, it has a clear advantage in that it is applicable to DNA samples which can be extracted simply by conventional methods.

To detect junction fragments efficiently, we used four rare cutting endonucleases, $A p a \mathrm{I}$, $B s t \mathrm{PI}, E c o \mathrm{RV}$, and $K p n \mathrm{I}$. These enzymes yielded larger DNA fragments from the genomic DNA than did HindIII or $B g l I I$ which are usually used to analyse the dystrophin gene. Since DNA fragments larger than $20 \mathrm{~kb}$ were difficult to separate by conventional electrophoresis on 0.7 to $1 \%$ agarose gel, we used electrophoresis of single stranded DNA to analyse digestion products of rare cutters. McMaster and Carmichael ${ }^{15}$ reported that the migration rate on agarose gel electrophoresis of single stranded DNA treated with glyoxal depends solely on the molecular weight and not on the nucleotide sequence. FastLane and Gold agarose were used because of their high mechanical strength at concentrations as low as $0.4 \%$. With these modifications, DNA fragments of 30 to $50 \mathrm{~kb}$, the mean size of introns of the dystrophin gene, ${ }^{6}$ were well separated. Blot hybridisation of the electrophoresed single stranded DNA was performed as easily as conventional Southern blotting.

No junction fragments were observed in six patients with $\mathrm{DMD} / \mathrm{BMD}$, even when our new method was used. In four out of the six patients, breakpoints of deletions were located in intron 44 , the largest intron of the dystrophin gene (about $180 \mathrm{~kb}$ ). ${ }^{8}$ In these cases, junction fragments might have been too large to separate by the electrophoretic technique we used. In the remaining two cases, junction fragments could be detected with restriction endonucleases other than those used in this study.

To find abnormalities in the entire coding region of the dystrophin gene by Southern blotting, each probe of the nine different subclones of dystrophin cDNA must be used separately, because the dystrophin gene contains 79 exons. ${ }^{17}$ The multiplex polymerase chain reaction is an excellent method for detecting large deletions in the dystrophin gene of affected probands, ${ }^{18} 19$ but it is difficult to quantify accurately the doses of DNA fragments. Recently, fluorescent dosage analyses of multiplex polymerase chain reactions have been reported for carrier diagnosis of DMD/BMD. ${ }^{20}$ The method described in this study is a useful addition to the methods currently available.

The use of our method is not limited to the study of $\mathrm{DMD} / \mathrm{BMD}$. It will be equally applicable to the diagnosis of other genetic diseases and the screening of candidate genes for rearrangements.
This work was supported by a Research Grant (5A-3-07) for Nervous and Mental Disorder from the Ministry of Health and Welfare, Japan.

1 Worton RG, Thompson MW. Genetics of Duchenne muscular dystrophy. Annu Rev Genet 1988;22:601-29.

2 Koenig M, Hoffman EP, Bertelson CJ, Monaco AP, Feener C, Kunkel LM. Complete cloning of the Duchenne muscular dystrophy (DMD) cDNA and preliminary genomic organization of the DMD gene in normal and affected individuals. Cell 1987;50:509-17.

3 Hu XY, Burghes AHM, Ray PN, Thompson MW, Murphy EG, Worton RG. Partial gene duplication in Duchenne and Becker muscular dystrophies. $\mathcal{F}$ Med Genet 1988;25: and Becker

4 Darras BT, Blattner P, Harper JF, Spiro AJ, Alter S, Francke U. Intragenic deletions in 21 Duchenne muscular dystrophy (DMD)/Becker muscular dystrophy (BMD) families studied with the dystrophin cDNA: location of breakpoints on HindIII and BglII axon-containing fragment maps, meiotic and mitotic origin of the mutations. Am f Hum Genet 1988;43:620-9.

5 Gillard EF, Chamberlain JS, Murphy EG, et al. Molecular and phenotypic analysis of patients with deletions within the deletion-rich region of the Duchenne muscular dystrophy (DMD) gene. Am f Hum Genet 1989;45:507-20.

6 Den Dunnen JT, Grootscholten PM, Bakker E, et al. Topography of the Duchenne muscular dystrophy (DMD) gene: FIGE and cDNA analysis of 194 cases reveals 115 deletions and 13 duplications. Am f Hum Genet 1989;45: 835-47.

7 Hu XY, Ray PN, Murphy EG, Thompson MW, Worton RG. Duplicational mutation at the Duchenne muscular dystrophy locus: its frequency, distribution, origin, and dystrophy locus: its frequency, distribution, origin, and phenotype-gen

8 Blonden LA, Grootscholten PM, Den Dunnen JT, et al. 242 breakpoints in the $200-\mathrm{kb}$ deletion-prone $\mathrm{P} 20$ region of the DMD gene are widely spread. Genomics 1991;10: 631-9.

9 Niemann-Seyde S, Slomski R, Rininsland F, Ellermeyer U, Kwiatkowska J, Reiss J. Molecular genetic analysis of 67 patients with Duchenne/Becker muscular dystrophy. Hum Genet 1992;90:65-70.

10 Hiraishi Y, Kato S, Ishihara T, Takano T, Quantitative Southern blot analysis in the dystrophin gene of Japanese patients with Duchenne or Becker muscular dystrophy: a high frequency of duplications. F Med Genet 1992;29: 897-901.

11 Speer A, Spiegler AWJ, Hanke R, et al. Possibilities and limitation of prenatal diagnosis and carrier determination for Duchenne and Becker muscular dystrophy using cDNA probes. 7 Med Genet 1989;26:1-5.

12 Blonden LA, den Dunnen JT, van Paassen HM, et al. High resolution deletion breakpoint mapping in the DMD gene by whole cosmic hybridization. Nucleic Acids Res 1989;17: 5611-21.

13 Lau YL, Srivastava G, Wong V, Liu YT, Ho FC, Yeung CY. Deletions, duplications and novel restriction fragment length polymorphism in Duchenne and Becker muscular dystrophies. Clin Genet 1992;41:252-8.

14 Herrmann BG, Frischauf AM. Isolation of genomic DNA. Methods Enzymol 1987;152:180-3.

15 McMaster GK, Carmichael GG. Analysis of single- and double-stranded nucleic acids on polyacrylamide and agardouble-stranded nucleic acids on polyacrylamide and agarAcad Sci USA 1977;74:4835-8.

16 Kato S, Tachibana K, Takayama N, Kataoka H, Yoshida MC, Takano T. Genetic recombination in a chromosomal translocation $\mathrm{t}(2 ; 8)(\mathrm{p} 11 ; \mathrm{q} 24)$ of a Burkitt's lymphoma cell line, KOBK101. Gene 1991;97:239-44.

17 Roberts RG, Coffey AJ, Bobrow M, Bentley DR. Exon structure of the human dystrophin gene. Genomics 1993; 16:536-8.

18 Chamberlain JS, Gibbs RA, Ranier JE, Caskey CT. Multiplex PCR for the diagnosis of Duchenne muscular dystrophy. In: Innis MA, Gelfand DH, Sninsky JJ, White TJ, eds. PCR protocols: a guide to methods and applications. San eds. PCR protocols: a guide to methods and
Diego: Academic Press, 1990:272-81.

19 Beggs AH, Koenig M, Boyce FM, Kunkel LM. Detection of $98 \%$ of DMD/BMD gene deletions by polymerase chain reaction. Hum Genet 1990;86:45-8.

20 Schwartz LS, Tarleton J, Popovich B, Seltzer WK, Hoffman EP. Fluorescent multiplex linkage analysis and carrier detection for Duchenne/Becker muscular dystrophy. $\mathrm{Am}$ 7 Hum Genet 1992;51:721-9.

21 Yau SC, Bobrow M, Mathew CG, Abbs SJ. Accurate diagnosis of carriers of deletions and duplications in Duchenne/ f Med Genet 1996;33:550-8. 